\title{
Predicting the Living Status of Homeless Youth: Living on the Street or in a Shelter
}

Information about the characteristics of street-living versus shelter-residing youth is vital for tailoring prevention and intervention efforts to the unique needs of runaway and homeless youth. The present study compared two samples of youth [street-living $(n=73)$ versus shelter-residing $(n=205)]$, between the ages of 14 to 17 years, on behavioral and emotional factors and service use. Based on the different characteristics of the two groups, the predictors explaining the living status of the runaways and homeless youth were explored. In general, street-living youth reported more severe substance use, depressive symptoms, and risky sexual behavior, but less lifetime service involvement compared to shelter-residing youth. The factors that predicted shelterresiding status were related to younger age, prior service care experience, more knowledge about HIV, and engaging in less delinquent and risky behavior. Given the little overlap among youth in service involvement and the greater severity faced by street-living youth, the conclusions highlight the need for increased funding and attention towards facilitating the ability of street-living youth to find and enter mental health and reintegration services.

Homeless youth are a diverse group due to their personal experiences and interaction with the social and institutional structures that they use. It is estimated that between 500,000 and 2.8 million youth remain homeless each year in the U.S. (Cooper, 2006). News reported by the Urban

Assistant professor, Department of Child and Family Studies, Yonsei University (mjkang@yonsei.ac.kr)

Key Words: Homeless youth, shelter-residing, street-living, substance use, risk behavior, service use
Institute in the U.S. indicated that nearly one in five children (19\%) run away before age 18 (George, 2010). Compared to the U.S., the ratios of runways and homeless youth in Korea are lower. According to the 2010 National Police Agency report, approximately 22,287 Korean children and adolescents (9-19 years of age) were reported to have at least one experience of running-away in Korea (Lee \& Choi, 2011). Based on the Korea National Research Report presented by the National Youth Policy Institute (2009), 3.1\% ( $n=86$ out of 2,788) of elementary school students, $8.1 \%$ ( $n=284$ out of 3,504 ) of middle school students, and $12.1 \%$ ( $n=418$ out of 3,458$)$ of high school students reported a running-away experience. The sample was randomly selected from 12 different provinces in Korea. In addition, the number of runaway cases of the female students that were reported to the National Police Agency increased from 7,099 to 13,462 within four years (2005 and 2009, respectively). Although the actual percentage of the Korean runaway adolescents might be lower than that of the U.S., the number of runaway youths is increasing. In addition, the lack of existing data on the number of street-living youths may be simply unrevealing the actual seriousness of the problem.

While research focused on homeless youth as increased, information regarding differences between shelter-residing and street-living youth is yet to be analyzed. Especially, most Korean studies on homeless or runaway youths focus only on runaway youths who reside in shelters or at least using some type of service care and very few Korean studies include the street-living youths as the subjects. The findings of 
these studies indicate that street-living youth experienced more violence victimization than the shelter-residing youths (Rhee, Noh, \& Lee, 2004), think more about suicide, are more depressed and experience more abuse (Noh, Kim \& Lee, 2005) than shelter-residing youths. The greater risk and severity of problems faced by street-living youths deem homeless youth an important issue to be investigated. The current social interest in welfare should focus on the welfare of shelter-residing youths as well as efforts to reduce the number of homeless youth living on the street; in addition, the findings be considered in the policy development of prevention/ intervention programs. Considering the need for the research in this area, the present study explores the factors that differentiate youths who decide to reside in shelters versus those who decide to live on the street. The factors explored for comparison between the two groups include some personal characteristics (age and gender), family background (number of individuals in the household when growing up, previous experience of abuse, and service care), and some psychological and behavioral attributes (depression, knowledge about HIV, and risky behaviors and delinquency). Such information is expected to provide a valuable direction to those who seek to intervene in the life trajectory of those who are homeless. This is especially salient because adolescents appear to be at a greater risk for living on the streets or being homeless (Robertson \& Toro, 1999) and more vulnerable to the long-term consequences of homelessness (National Coalition for the Homeless, 1999).

Definitions of homeless youth vary. In 1983, the Inter-nongovernmental Organizations defined a "street child" as any child for whom the streets are either an abode or a critical source of income/ survival. One of the early official government documents examining homelessness in the United States, The Stuart B. McKinney Act (1987), defined a homeless youth as an individual under the age of eighteen who lacks parental, foster, or institutional care. Runaway youth are often defined as youth who have left home for 24 hours without the permission of a parent or a guardian (U.S. Department of Health and Human Services, 1999).
The Runaway and Homeless Youth Act established Basic Center Programs that includes funding for runaway shelters where youth can reside for short periods (up to fourteen days) while efforts are made to reintegrate them with their families or the foster care system (Cooper, 2006). This act did not establish services for unaccompanied minors or street youth. The two groups are not mutually exclusive because there is the possibility that some shelter youth may eventually become street youth.

Some differences between shelter-residing and street-living youth have been noted (though systematic comparison of the two groups is rare). Shelterresiding youth tend to be younger and often have never spent a night on the streets (Robertson \& Toro, 1999). Most street-living youth do not reach the shelter system (US House of Representatives, 1992) and do not tolerate the possibility of reuniting with their families. Kipke et al. (1995) estimated that $70 \%$ of homeless and runaway youth do not use shelters (in part) because they do not want their families contacted as required by shelters and because they have great difficulty living in shelters (De Rosa et al., 1999).

Some evidence suggests that street-living youth fare worse than runaways who have not spent time on the street. Street-living youth are more vulnerable and more exposed to street crime and violence than shelter-residing youths who may be more protected from this type or level of activity (Patel \& Greydanus, 2002). These findings have prompted some to advocate for the separate examination of and intervention development for street-living youth versus more stable runaway youth (Clements et al., 1997; Haber and Toro 2004). Findings from previous studies show that the street-living youth report higher levels of soft-drug use, higher intravenous (IV) drug use, less condom use and other high-risk behavior (Clements et al., 1997; Van Leeuan et al., 2004). Clements et al. (1997) noted the importance of examining street based youth as separate from other runaway youth where high-risk social milieus may be a major cause of higher levels of risk behavior reported by street-living youth. Similarly, Haber and Toro (2004) noted that it may be useful to consider presence on the street as a marker of 
severity, as problematic behaviors and risk appear to increase with time spent on the streets. Shelter recruited and street recruited youth are not necessarily a completely dichotomous group (some shelter youth may spend time on the streets and some street youth may spend time at a shelter); however, research findings suggest that they are sampled at a different point in their homeless trajectory and may present differing behavioral and emotional profiles.

In understanding the differences between these two groups, the failure to have a supportive and functional family (a stable primary activity setting that youth can return to and use as a launching pad for other positive micro-systems) may be the single largest factor associated with adolescent homelessness (Rotheram-Borus, Koopman, Haignere, \& Davies, 1991). Teare, Furst, Peterson, and Authier (1992) found in their sample of shelter-residing youths, that those who did not return to a primary family system had higher levels of hopelessness, suicidal behavior and ideation, and reported more family problems than those who were able to return

Teare et al's study was conducted with shelter youth; however, it will be equally important to know if street-living youth show a similar pattern to shelter-residing youth. Youth who live on the streets and do not return to a home setting (weakening or extinguishing critical linkages) might be likely to report more family problems and to suffer from more internalizing problems than shelter-residing youth who return home. Alternatively, it is possible that, shelter-residing youth who do not return home (instead return to foster care) and street-living youth who have successfully escaped negative family environments, will improve their emotional and behavioral functioning. Some suggest that among street-living youth, problems experienced prior to homelessness are exacerbated by the separation from their family and from continued negative experiences of victimization, loneliness and violence while living on the streets (Patel \& Greydanus, 2002). Whitbeck and Hoyt's (1999) risk amplification model addresses the mechanisms through which street experiences amplify negative developmental effects that originate in the family. According to this model, the developmental effects of early negative family interactions are carried onto the streets and result in non-conventional peer associations with deviant behavior that increase the risk for physical and sexual victimization. While the most positive aspects of having a family setting as a primary part of the meso-system are lost, the most negative aspects are maintained and/or exacerbated.

Previous studies indicated some of the common reasons adolescents give for being homeless. Some of the factors included are family conflict (Lewit \& Baker, 1996; Office of Technology Assessment, 1991) as well as physical and sexual abuse (Office of Technology Assessment, 1991; Susser, Moore, \& Link, 1994). According to Kurtz, Jarvis and Kurtz (1991), the number of individuals living in the household was also considered as one of the variables related to homelessness. For example, one child in eight members is expected to leave home prior to age 18 , but if more than eight persons live in the home, then, one in four children are estimated to leave home prematurely prior to reaching age 18 . Thus, given the potential impact of the number of individuals living in the household on homelessness, this factor was considered to be compared between the shelter-residing and street-living youths.

There are also other and sometimes overlapping reasons including family crises, drug and alcohol abuse in the home, and poverty (National Coalition for the Homeless, 2000). As noted above, minors have the option of going to specifically designed runaway shelters, usually under the aegis of the Runaway and Homeless Youth Act. If homeless youth choose not to use these types of shelters, their options become severely limited because it is difficult for homeless youth to find even semipermanent housing (minors cannot independently sign leases) and there is limited access to health services (Ensign \& Bell, 2004). This leaves homeless youth (especially those who do not use shelters) at an increased risk for a myriad of physical, mental, and psychosocial health risks (Roy et al., 2000).

Overall, little systematic examination on the differences in activity patterns between shelterresiding youth and street-living youth as been conducted, though several researchers have noted 
that street-living youth have more problematic behaviors than shelter-residing youth as noted earlier (e.g., Robertson \& Toro, 1999; Kipke et al., 1995). The current study addresses this gap by comparing a sample of shelter recruited youth to a sample of street recruited youth between the ages of 14 and 17. Interventions tailored to a homeless youth population are important; however, recognition of the differences within the homeless youth population (and the possible reasons for those differences) are necessary to guide intervention efforts (Wagner, Carlin, Cauce \& Tenner, 2001). For example, Chamberlain and MacKenzie (2004) assert that intervention and prevention efforts should consider that youth go through various stages before they selfidentify as a homeless person, with different interventions needed at different points in the homeless trajectory.

In the current study, youths' self-report on a number of socially problematic behaviors such as substance use, depression, and delinquency for a comparison of shelter-residing and street-living youths. All youth in the current study were involved in substance abuse and this study focuses on a subsample of homeless youth. While this limits the generalizability of study findings, many researchers report that substance abuse is a significant concern among runaway and homeless youth (e.g., Baer $e t$ al., 2003; Kipke et al., 1997). Based on primary microsystem activities and probable meso-systems based on those activities - street recruited youth were expected to report significantly increased substance use, health risks, delinquency and depressive symptoms than shelter-residing youth. Street-living youth, compared to shelter recruited youth were also expected to report a riskier family environment that included more running-away episodes, child abuse, and a higher number of people in the household while growing up or less number of years raised by both parents. Research suggests that depression, substance use and health risks differ depending upon age and gender of the runaway (Molnar et al., 1998; Unger et al., 1998); therefore, these variables were considered in the analyses. The results from this study are informative for service provisions and policy efforts.

\section{METHODS}

\section{Overview and Participants}

Data were collected from modified convenience samples (shelter youth were a convenience sample [out of of necessity] while street youth were a combination of snowball, probability sampling, and convenience) in a large U.S. southwestern urban center. Shelter-residing youth were approached through two local runaway shelters while street youth were approached through a local drop-in center. These data were part of larger studies that examined the impact of treatment on substance abusing shelter-residing and street-living youth. This research was approved by the university institutional review board. The inclusion criteria for the larger study of shelter youth required that the youth: (1) be between the ages of 12 to 17 , (2) have the legal option of returning to a home situation (including foster care or extended family members), and (3) meet DSM-IV criteria for substance use disorders as assessed by the Computerized Diagnostic Interview Schedule for Children (CDISC; Shaffer, 1992). The inclusion criteria for the larger street youth study was that youth: (1) be between the ages of 14-20, (2) meet DSM-IV criteria for a substance use disorder, and (3) meet the criteria for homelessness as defined by the U.S. Department of Health and Human Services (1999) as "a situation in which a youth has no place of shelter and is in need of services and a shelter where he or she can receive supervision and care." In order to reduce heterogeneity, only youth between the ages of 14 and 17 years were included in the current study. The final sample comprised 205 shelter-living youth and 73 street-living youth.

\section{Procedure}

Shelter-Residing Youth Eligible shelter youth were approached by research assistants (RAs) in the shelters. If the adolescent was eligible and consented to have their parents contacted and to participate in the study, the parent was contacted. Upon parental consent, a youth assessment was then conducted. The assessment required up to 2 hours and clients received $\$ 25$ at the completion of the assessment. 
Street-Living Youth Eligible street youth were approached by research assistants through the local drop-in center. Youth who accessed the center had heard about it through word of mouth and through the outreach efforts of the center staff. When youths walked through the center, potentially eligible youth were screened for participation and the assessment battery was administered by the RA to consenting participants. The data were part of larger studies that examined the impact of treatment on substance abusing shelter-residing and street-living youth. However, the data used in this study was collected before the treatment started and the subjects were carefully selected for eligibility. To be eligible for the study, youth had to meet the age criteria (14-17 yrs.), agree to participate in the assessment and treatment intervention, and meet the homelessness criteria defined as "a situation in which a youth has no place of shelter and is in need of services and a shelter where he or she can receive supervision and care" (U.S. Department of Health and Human Services, 1999). Youths who live with parents or other family members were not eligible as study participants on street-living youths. At the time of the data collection, the group included (as street-living youths) were those who were not using any shelter or service system, but who lived on the street and had no permanent place to stay. The places they reported to use were areas such as parks, streets, libraries, or a friend's house. The youth was the only data source for all cases. The assessment required approximately 2 hours to complete and was conducted in offices within the drop-in center. Youths had left the center after completing the assessments and receiving the stipend. Youth were also provided a care package that included toiletries, a blanket, socks, underwear, and food items. Those who needed any further assistance or requested services but were not eligible for drop-in services were referred to local community agencies that included the local university's Mental Health Center and Healthcare for the Homeless.

\section{Measurements}

Demographic and Homeless Experience Form All youth were asked questions about their age, gender, ethnicity, parental information, number of people in the household of their family of origin, system care involvement, school enrollment, number of runningaway episodes, and homeless experiences. The living status of the participants was defined and categorized according to the living status at the time of the assessment. However, the prior living status was also assessed to see their lifetime street or shelter experiences.

Substance Use The Form 90 (Miller \& Del Boca, 1994) was used to assess the frequency of alcohol and other substance use 90 days prior. Kappas for different drug classes range from .74 to .95 (Tonigan, Miller, \& Brown, 1997; Westerberg, Tonigan, \& Miller, 1998). In this study, the frequency of reported alcohol and drug use was applied as one of the variables for to compare street-living versus shelterresiding youth. The reliability coefficient was .85 .

Health Risk Behaviors The Health Risk Questionnaire (HRQ; Slesnick \& Prestopnik, 2005) incorporates items from the Health Risk Survey (Kann et al., 1989) and the Homeless Youth Questionnaire (Johnson et al., 1996) to address a wide range of HIV knowledge and risk behaviors. In the current study, the HIV knowledge of adolescents and their risk behaviors were asked through a self-report questionnaire. The overall HIV knowledge score developed by Kann et al. (1989) includes 17 yes/no items. In addition to individual risk behavior items, the overall HIV risk score developed by Johnson et al. (1996) was used as one of the predictors to explain the living status of the youths. The overall HIV risk score includes the aggregate of seven items: (a) intravenous (IV) drug use, (b) multiple sexual partners, (c) high-risk sexual partners (including prostitutes, IV drug users, and persons who are HIV positive), (d) condom use, (e) anal sex, (f) survival sex (trading sex for money, food or shelter), and (g) ever having had an STD. Internal reliabilities for the current sample were alpha $=.61$ for the HIV knowledge scale (range: 0-17) and alpha=.73 for the HIV risk scale (range 0-7). Although the alpha value was not considered as high, the overall score was used in the logistic regression because of the limits on the number of 
variables in the model. The reliability score did not significantly increased even if some of the items were deleted; therefore, all of the items were used as a whole. However, the individual items were compared between the groups using the $t$-test and chi-square test as one of the ways to partially compensate the limitation of the low internal reliabilities of the overall HIV risk score.

Depression Depressive symptoms were measured using the Beck Depression Inventory (BDI-II; Beck, Steer \& Brown, 1996). The BDI-II is a 21 -item selfreport instrument to measure depressive symptoms in adults and adolescents age 13 and over. In the current sample, the internal reliability for the overall depression score was alpha $=.91$.

Individual Problem Behaviors The National Youth Survey Delinquency Scale (NYSDS; Elliott \& Huizinga, 1983) is a structured interview used as a measure of delinquent behavior. The data collected from the interview is coded into either a ratio or ordinal scale. For example, for the question, "How many times in the past 12 months have you stolen (or tried to steal) a motor vehicle, such as a car or motorcycle?" were answered as the 'number of times stealing' that was coded as a ratio scale. If their answers for the number of times stealing were, "10 or more times" the next question asked was "How often (have you stolen/have you tried to steal)?" and their answers were categorized and rated as an ordinal scale (i.e., Once a month $=1$, Once every 2-3 weeks $=2$, Once a week $=3,2-3$ times a week $=4$, Once a day $=5,2-3$ times a day=6). If their answers for the number of times stealing were, "1 or more" the next question asked was "How old were you when you first did this?" Their answers were coded as a ratio scale. The measure includes 5 subscales: General theft, crimes against persons, index offenses, drug sales and total delinquency. The NYSDS has displayed adequate test-retest reliability and criterion validity (Elliott \& Huizinga, 1983). The overall total delinquency scale score was utilized as a dependent measure in this study and the Cronbach's alpha for this sample was .65. Some of the individual items were deleted as an attempt to increase the internal reliability. However, the alpha did not increase significantly, as a few items were deleted, and there was no particular item considered unrelated to the measuring construct. Thus, the total score of NYSDS was used with the limitation.

\section{Overview of Analyses}

In bivariate analyses, differences between streetliving versus shelter-residing youth in their demographic characteristics were examined and their behavioral outcomes were compared using the paired $t$-tests and Chi-square tests. Multivariate logistic regression was conducted to explore which variables predict youth living status (street-living versus shelter-residing). The living status was dummy-coded, with "shelter-residing" assigned as a reference group (0). Three separate multivariate models were undertaken. The first model included demographic variables only. In the second model, information about the earlier personal experiences (child abuse and a ward of state) was added. In the final model, current problematic behaviors that included substance use, high-risk behavior and depression were entered in addition to the included variables. The set of variables were entered to control for the factors that happened earlier in life and to examine the unique contribution of concurrent behavior patterns.

\section{RESULTS}

\section{Descriptive Statistics Comparing Shelter-Residing Versus Street-Living Youth}

Study participants $(N=278)$ consisted of $153(55 \%)$ females and $125(45 \%)$ males. Ethnicity included Anglo ( $n=109,39.2 \%)$, Latino/Latina $(n=122,43.9 \%)$, Native-American $(n=16,5.8 \%)$, African-American $(n=13,4.7 \%)$, and mixed ethnicity $(n=18,6.5 \%)$. The mean age at the initial assessment was 15.5 years $(\mathrm{SD}=1.08) ; 15.7 \quad(\mathrm{SD}=1.06)$ for males and 15.3 $(\mathrm{SD}=1.06)$ for females. Participants in the streetliving category were older (mean=15.9, SD 1.1) on average than shelter-residing youth (mean $=15.4$, $\mathrm{SD}=1.0$ ). No differences were found between shelterresiding and street-living youth on gender or race/ 
ethnicity.

Demographic characteristics and other information such as school enrollment, system care involvement, number of years raised by parents, history of abuse, and homeless experience that characterized the two samples are presented in Table 1. Categorical variables were compared using Chi-square test and continuous variables with mean scores were compared using the paired $t$-test. Chi-square test compares the percentage of the frequency within each group. For example, comparing whether there are differences in the gender ratio by the shelter

Table 1. Comparison between Shelter-Residing and Street-Living Youth in their Demographic and Selected Characteristics

\begin{tabular}{|c|c|c|c|}
\hline & Shelter-residing $(n=205)$ & Street-living $(n=73)$ & $\left(\chi^{2}\right)^{\mathrm{a}}$ \\
\hline Gender, Age & $n(\%)$ & $n(\%)$ & \\
\hline Female & $111(54.1 \%)$ & $42(57.5 \%)$ & .25 \\
\hline Male & $94(45.9 \%)$ & $31(42.5 \%)$ & .25 \\
\hline Average Age $(M, \mathrm{SD})$ & $15.4(1.0)$ & $15.9(1.1)$ & $-3.50^{* *}(t)^{\mathrm{b}}$ \\
\hline \multicolumn{4}{|l|}{ Ethnicity } \\
\hline Anglo & $74(36.1 \%)$ & $35(47.9 \%)$ & 3.17 \\
\hline Hispanic & $93(45.4 \%)$ & $29(39.7 \%)$ & .70 \\
\hline Native American & $13(6.3 \%)$ & $3(4.1 \%)$ & .49 \\
\hline African-American & $11(5.4 \%)$ & $2(2.7 \%)$ & .83 \\
\hline Mixed Ethnicity & $14(9.8 \%)$ & $4(12.5 \%)$ & .16 \\
\hline \multicolumn{4}{|l|}{ Other Characteristics } \\
\hline Currently enrolled in school & $100(48.8 \%)$ & $29(39.7 \%)$ & 1.33 \\
\hline Ever in foster care & $61(29.8 \%)$ & $12(16.4 \%)$ & $5.56^{*}$ \\
\hline Ever in a group home & $67(32.7 \%)$ & $13(17.8 \%)$ & $6.43^{*}$ \\
\hline Ever a ward of the state & $54(26.3 \%)$ & $9(12.3 \%)$ & $5.59^{*}$ \\
\hline Ever in juvenile detention & $95(46.3 \%)$ & $27(37 \%)$ & 1.48 \\
\hline Ever arrested & $134(65.4 \%)$ & $47(64.4 \%)$ & .02 \\
\hline Ever attempted suicide & $76(37.1 \%)$ & $29(39.7 \%)$ & .32 \\
\hline Ever physically abused & $104(50.7 \%)$ & $31(42.5 \%)$ & 1.06 \\
\hline \multirow[t]{2}{*}{ Ever sexually abused } & $68(33.2 \%)$ & $26(35.6 \%)$ & .28 \\
\hline & $(M, \mathrm{SD})$ & $(M, \mathrm{SD})$ & $t^{\mathrm{b}}$ \\
\hline No. of people in household growing up & $4.45(1.7)$ & $4.70(2.2)$ & -1.02 \\
\hline No. of years raised by both parents & $5.5(6.1)$ & $4.1(5.7)$ & $1.73^{t}$ \\
\hline \multicolumn{4}{|l|}{ Homeless Experience } \\
\hline Age first homeless/with no place to stay & $13.2(3.4)$ & $13.7(2.7)$ & -1.02 \\
\hline No. of times without a place to live & $\begin{array}{l}3.97(10.52) \\
{[.96(.94)]^{c}}\end{array}$ & $\begin{array}{l}54.13(234.02) \\
{[1.71(1.79)]^{\mathrm{c}}}\end{array}$ & $\begin{array}{l}-2.95^{* *} \\
-4.48^{* * * * *}\end{array}$ \\
\hline No. of times running-away & $4.6(10.2)$ & $9.5(20.8)$ & $-2.60^{*}$ \\
\hline Ever stayed on the street $^{d}$ & $16(7.8 \%)$ & & \\
\hline Ever stayed in a shelter & & $25(34.2 \%)$ & \\
\hline
\end{tabular}

Note. ; ${ }^{t} p<.10,{ }^{*} p<.05,{ }^{* *} p<.01,{ }^{* * * *} p<.0001$.

${ }^{a} p$ values based on chi-square tests, $d f=1$

${ }^{\mathrm{b}} p$ values based on two-tailed independent paired $t$-test, $d f=276$

'Due to skewness $(>2)$ in the means of "number of times without a place to live," log transformed values are provided and compared.

${ }^{\mathrm{d}}$ Ever lived in abandoned buildings, squats, bus/train stations, airports, streets, parks, or alleys over the last 30 days. 
versus street group percentage of females within the shelter group [54.1\%; 111/205] was compared to [57.5\%; 42/73]. The difference of this percentage was not considered statistically significant. Youth from the shelter were more likely to report a history of being involved with system care (foster care, group home, or a ward of the state; $p<.05)$. Regarding the homeless experiences, few shelter-residing youth $(7.8 \%)$ reported that they had lived on the streets and some street-living youth (34.2\%) reported that they had utilized runaway shelter services. When episodes related to homeless experience were compared, street-living youth reported more running-away episodes $(p<.05)$ and number of times having no place to live $(p<.001)$ than the shelterresiding youth.

Comparisons among street-living versus shelterresiding youth on substance use, sexual risk behavior, depressive symptoms and delinquent behavior are summarized in Table 2. Street youth reported a significantly higher percentage of days using alcohol and drugs $(p<.0001)$. However, when

Table 2. Comparison between Shelter-Residing and Street-Living Youth and Substance Use, Problematic Behavior and HIV Risk Behavior

\begin{tabular}{|c|c|c|c|}
\hline & Shelter-residing $(n=205)$ & Street-living $(n=73)$ & $t^{\mathrm{a}}$ \\
\hline Substance Use ${ }^{\mathrm{c}}$ & $(M, \mathrm{SD})$ & $(M, \mathrm{SD})$ & \\
\hline Drug and Alcohol Use & $50.31(32.57)$ & $80.16(29.12)$ & $-6.87^{* * * * *}$ \\
\hline Alcohol Use & $16.64(21.00)$ & $9.86(14.26)$ & $2.55^{*}$ \\
\hline Drug Use & $44.37(35.00)$ & $55.64(32.08)$ & $-2.40^{*}$ \\
\hline \multicolumn{4}{|l|}{ Problematic behaviors } \\
\hline NYSDS Delinquency score & $\begin{array}{l}353.08(778.91) \\
{[4.21(2.06)]^{d^{d}}}\end{array}$ & $\begin{array}{l}71.15(85.61) \\
{[2.98(1.98)]^{d}}\end{array}$ & $\begin{array}{l}3.04^{* *} \\
4.37^{* * * * *}\end{array}$ \\
\hline \multirow[t]{2}{*}{ BDI Depression score } & $12.88(10.17)$ & $17.15(10.87)$ & $-3.01^{* *}$ \\
\hline & & & $\left(\chi^{2}\right)^{b}$ \\
\hline Health risk behavior & $\mathrm{n}(\%)$ & $\mathrm{n}(\%)$ & \\
\hline Ever injected drugs & $24(11.7)$ & $4(5.5)$ & 2.31 \\
\hline Ever shared needles & $3(1.5)$ & $1(1.4)$ & .003 \\
\hline Ever had sex with someone & $149(72.7)$ & $67(91.8)$ & $11.33^{* * *}$ \\
\hline Number of sex partner 3 & $102(49.8)$ & $48(65.8)$ & $5.55^{*}$ \\
\hline Ever had sex with high risk sex partner $^{\mathrm{e}}$ & $11(5.4)$ & $4(5.5)$ & .001 \\
\hline Usually use condom & $102(49.8)$ & $49(67.1)$ & $6.54^{*}$ \\
\hline Ever had anal sex & $21(10.2)$ & $11(15.1)$ & 1.23 \\
\hline Ever had survival sex & $11(5.4)$ & $3(4.1)$ & .18 \\
\hline \multirow[t]{2}{*}{ Ever had an STD } & $18(8.8)$ & $6(8.2)$ & .02 \\
\hline & $(M, \mathrm{SD})$ & $(M, \mathrm{SD})$ & $t^{\mathrm{a}}$ \\
\hline Age of first sexual intercourse & $13.44(1.72)$ & $12.55(4.10)$ & $2.28^{*}$ \\
\hline HIV risk behavior in lifetime ${ }^{f}$ & $1.41(1.15)$ & $2.34(.74)$ & $-6.33^{* * * *}$ \\
\hline HIV knowledge (out of 17) & $13.89(2.46)$ & $12.41(1.93)$ & $4.65^{* * * * *}$ \\
\hline
\end{tabular}

Note. ${ }^{*} p<.05,{ }^{* *} p<.01,{ }^{* * *} p<.001,{ }^{* * * *} p<.0001$.

${ }^{a} p$ values based on two-tailed independent paired $t$-test, $d f=276$

${ }^{\mathrm{b}} p$ values based on Chi-square tests, $d f=1$

${ }^{\mathrm{c}}$ Percentage days of substance use during the last 90 days

${ }^{\mathrm{d}}$ Due to skewness $(>2)$ in the means of NYSDS total score, log transformed values are provided and compared.

${ }^{\mathrm{e}}$ Includes prostitutes, IV drug users, and persons who are HIV positive

${ }^{\mathrm{f}}$ Includes: injected drug use; multiple sexual partners; high-risk sexual partners; condom use, defined as whether or not the respondent or partner usually uses a condom; anal sex; survival sex; and ever having an STD. (score range: 0-7). 
the levels of alcohol and drug use were independently assessed, shelter youth reported more alcohol consumption $(p<.05)$ and street youth reported more drug use $(p<.05)$. Street youth reported significantly higher depressive symptoms $(p$ $<.01)$, whereas shelter youth reported significantly higher delinquency $(p<.001)$.

\section{Predicting Living Status}

For predicting living status, thirteen independent variables were entered in three blocks (See Table 3). In Model 1, demographic characteristics, including age and gender were included. Only age $[\operatorname{Exp}(B)=$ 1.53; $95 \%$ Confidence Interval $(\mathrm{CI})=1.16-2.02$; $p<.01)]$ was found to predict belonging to living status (street or shelter). The age being younger predicted an increase in the likelihood of belonging to the shelter. In Model 2, six additional characteristics were added [previous experiences in a supportive or adverse environment (i.e., school enrollment, ever being a ward of state, years raised by both parents, number of running-away episodes, and ever being physically and sexually abused)]. The addition of these variables significantly improved the fit of the model. Age still remained statistically significant and being a ward of state significantly predicted a decrease in the likelihood of belonging to the street $[\operatorname{Exp}(B)=.25 ; 95 \% \mathrm{CI}=0.10-0.64 ; p<.01)]$.

Table 3. Multivariate Logistic Regression Analyses Predicting Living Status of Study Participants $(n=205$ Shelter (0); $n=73$ Street (1))

\begin{tabular}{|c|c|c|c|c|c|c|}
\hline & \multicolumn{2}{|c|}{ Model 1} & \multicolumn{2}{|c|}{ Model 2} & \multicolumn{2}{|c|}{ Model 3} \\
\hline & $B^{\mathrm{a}}$ & $\operatorname{Exp}(B)^{\mathrm{b}}$ & B & $\operatorname{Exp}(B)$ & B & $\operatorname{Exp}(B)$ \\
\hline \multicolumn{7}{|l|}{ Demographics } \\
\hline Age & .43 & $1.53^{* * *}$ & .46 & $1.58^{* *}$ & .40 & $1.49^{t}$ \\
\hline Gender $^{\mathrm{c}}$ & .57 & $1.77^{t}$ & .45 & 1.57 & -.33 & .72 \\
\hline \multicolumn{7}{|l|}{ Other experiences } \\
\hline School enrollment ${ }^{\mathrm{d}}$ & & & -.05 & .95 & .93 & $2.54^{t}$ \\
\hline Ever a ward of state ${ }^{\mathrm{d}}$ & & & -1.37 & $.25^{* *}$ & -1.01 & .36 \\
\hline Years raised by parents & & & -.04 & .96 & -.04 & .96 \\
\hline Ever physically abused $^{\mathrm{d}}$ & & & -.49 & .61 & -.48 & .62 \\
\hline Ever sexually abused $^{\mathrm{d}}$ & & & .19 & 1.21 & .66 & 1.94 \\
\hline No. of running-away episodes & & & .03 & 1.03 & .05 & $1.05^{t}$ \\
\hline \multicolumn{7}{|l|}{ Behavior patterns } \\
\hline Alcohol and drug use & & & & & .04 & $1.04^{* * * * *}$ \\
\hline HIV risk behavior & & & & & 1.00 & $2.69^{* * * * *}$ \\
\hline HIV knowledge & & & & & -.51 & $.60^{* * * * * *}$ \\
\hline Depression & & & & & -.01 & .99 \\
\hline Delinquency & & & & & -.01 & $.99^{* * * * * *}$ \\
\hline Constant & -8.10 & .00 & -8.05 & .00 & -3.92 & .02 \\
\hline Model $\chi^{2}$ & & $11.24^{* *}$ & & $31.14^{* * * * *}$ & & $145.85^{* * * * *}$ \\
\hline Change in Model $\chi^{2}$ & & $11.24^{* *}$ & & $19.91^{* *}$ & & $114.71^{* * * * *}$ \\
\hline
\end{tabular}

Note. ${ }^{t} p<.10,{ }^{* *} p<.01,{ }^{* * *} p<.001,{ }^{* * * *} p<.0001$.

${ }^{a}$ The weighting value in the equation, which indicates the effect of predictor on the outcome (positive value indicate occurrence of youth being in street rather than shelter).

${ }^{\mathrm{b}}$ An indicator of the proportionate change in odds resulting from a unit change in the predictor (=odds ratio). If the value is greater than 1 then it indicates that as the predictor increases, the odds of the outcome occurring (youth being in street) increase. Conversely, if it is less than 1 then it indicates as the predictor increases, the odds of outcome (street-living) occurring decrease.

${ }^{c}$ male $=1$, female $=2 ;{ }^{d}$ yes $=1$, no $=0$. 
Finally, in Model 3, problematic behavior patterns (i.e., substance use, HIV risk behavior, depressive symptoms and delinquency) were added. Except for the depression score, all variables added in this block were statistically significant and improved the model fit. However, with the addition of these behavior problem variables, demographic and other early experience variables became nonsignificant. For every unit increase in HIV risk behavior scores, the likelihood of a person living on the streets increased almost three times $[\operatorname{Exp}(B)=$ 2.64; 95\% CI $=1.70-4.26 ; p<.0001)]$. Having more knowledge about HIV significantly decreased the likelihood of living on the streets $[\operatorname{Exp}(B)=.60 ; 95 \%$ $\mathrm{CI}=0.49-0.75 ; p<.0001)]$. Each unit increase in the percent days of alcohol and drug use increased the likelihood of a person living on the streets $[\operatorname{Exp}(B)=$ 1.04; 95\% CI=1.02-1.05; $p<.0001)]$. Each unit increase of the NYSDS delinquency score decreased the likelihood of living on the streets $[\operatorname{Exp}(B)=.99$; $95 \% \mathrm{CI}=0.99-0.99 ; p<.0001)]$.

\section{DISCUSSION}

This study showed that street youth report more severe substance use, depressive symptoms and risky sexual behavior, but less lifetime service involvement compared to shelter-residing youth. Street-living and shelter-residing youth reported similar level of childhood abuse history, suicide attempts and number of arrests. This study systematically compared street-living versus shelter-residing youth on emotional and behavioral factors, and service use is quite rare regardless of its importance. It is believed that the data provided in this study may contribute to raise awareness on the necessity of using a different approach for different types of homeless youth by paying more attention to street-living youth.

The findings from this study support prior research showed more severe mental health issues and sexual risk behavior among street-living youth compared to more stable youth (Clements et al., 1997; Van Leeuwan et al., 2004). Although streetliving youth used drugs more frequently than shelter-residing youth, shelter-residing youth used alcohol more frequently than street-living youth. This finding might represent the level of accessibility of drugs/alcohol for the two groups. For example, illicit drugs are likely more easily accessed by streetliving youth than by shelter-residing youth, accounting for the greater frequency of use. Finally, compared to shelter recruited youth, street youth reported more running-away from home and less lifetime system involvement. These findings can most logically be attributed to the differences of shelters and the streets as activity settings as well as to the evolution of meso-systems of individuals in the two different populations. It is important to note that an ecological model takes a transactional view of development (Sameroff 1983). Tendencies develop over time and across social systems. A youth from a dysfunctional family may be more likely to wind up on the streets; however, street experiences may be more likely to promote a meso-system that weakens or cuts off links to positive activity settings - in particular the family.

There are several potential explanations for the higher problematic behaviors reported among streetliving youth and this is why research on troubled youth needs to take an ecological/transactional perspective. It is difficult to know whether these problems were of greater severity even prior to homelessness or whether differences occurred after street/shelter involvement but it is believed that there are bi-directional relationships involved, and ecologically legitimate interventions may be conducted based on the understanding of this mutual relationships. Prior research suggests that the lack of connection to family is related to depression and poorer long-term outcomes for youth (Teare et al., 1992). The current study similarly showed higher depression scores among street-living youth compared to shelter-residing youth who return home. Of interest is that no differences were found among youth who reported experience of physical and sexual abuse, suggesting that family trauma is similar among the shelter-residing and street-living youth. However, significantly more shelter-residing youth reported having lived in a group or foster home setting and indicated linkages that are more positive. These linkages were able to provide 
opportunities to receive support that could possibly lead to more positive decisions based on an improved socially anchored self-perception and greater levels of self-efficacy. The disenfranchisement of street-living youth to social systems which can link these youth to mental health support and other service systems likely perpetuates pre-existing problematic behaviors by casting them socially adrift and making them feel they will find little support or benefit by connecting with these service systems.

Many note that homeless street-living youth avoid contact with higher level social systems (representatives of exo-system institutions), have low levels of trust with those outside their micro-system and lack instrumental social capital (e.g., McCarthy \& Hagan, 1995; Robertson \& Toro, 1999). Interventions with street-living youth are often focused on connecting these youth to resources (outreach work) and providing them the tools to help them improve their life situation (case management, group or individual therapy). It is considered that the ecological system approach to understanding and intervening in youth homelessness to be a useful theoretical model because it offers a context for understanding the behavior of homeless youth on a number of levels.

First, the ecological systems model helps to understand the transactional nature of the development of meso-systems of troubled youth. There seems to be a relationship between the structure and function of the family setting and running-away/homeless trajectories. At the same time there seems to be a relationship between problematic behavior endemic to street life and the degradation of family as part of the youth's mesosystem. Second, the ecological approach helps to understand the difficulties and influences youth face living on the street that can develop into difficulties and influences that may accelerate problems and cut youth off from positive activity settings. The more fluid and the less safe the primary setting, the more difficult it can be for the youth to deal constructively with developmental, emotional, and social issues. Third, the more fluid the primary setting then the more likely homeless youth will encounter secondary settings where there is dangerous and antisocial behavior. It then becomes important to put social workers, outreach workers and therapists in place who can meet and work with youth in their ecological context to establish linkages to more stable micro-systems. Fourth, an ecological model suggests the importance of developing social service agencies that meet the needs of youth who live on the far margins of society. While some cities offer drop-in centers for youth to access services, many other cities do not have services available for streetliving youth. Paradoxically, the further on the margins a youth is, the more they are separated and that can provide them with a sense of stability and positive linkages. Even if linkages to family settings are irreparably damaged, social services agencies must work to establish settings that serve many of the same core functions for these youth. Future longitudinal research might show that those youth who live on the streets have different coping or interpersonal styles (greater independence) than youth who never live on the streets. These youth might assess assistance programs such as runaway shelters or foster care as unable to meet their needs, and avoid programs to instead survive on their own.

More street-living compared to shelter-residing youth reported having multiple sex partners; however, street-living youth reported a higher frequency of condom use. While higher HIV risk behaviors among street-living youth compared to non-street-living youth have been reported by others (Halcon \& Lifson, 2004; Rotheram-Borus et al., 2003), more frequent condom use among streetliving youth compared to more stable youth is contrary to the findings of prior studies. Possibly, street youth sampled in this study used condoms more frequently because condoms were more easily accessed through the drop-in center.

Higher HIV risk behavior and lower knowledge about HIV were significant predictors of living status. Having poorer knowledge about the possible pathways of HIV infection and the consequences of sex-risk behavior were one of the major predictors that explained the decision to stay on the street. Street-living youth were engaged more in higher HIV risk behavior. Street-living youth have health, behavioral and emotional issues that go beyond 
shelter-residing youth. These personal difficulties are likely accentuated by lack of access to services and the ecology of survival on the streets. However, it is difficult to determine whether the more severe problems observed among street youth were of greater severity prior to homelessness or whether the differences occurred after homelessness.

Contrary to expectations, the shelter-residing youth reported more delinquent behavior than street-living youth. This finding was not expected as street-living youth often survive by engaging in illegal subsistence strategies (Robertson \& Toro, 1999). However, Unger et al. (1998) found comparable levels of illegal subsistence strategies among street youth and runaway youth. In the current sample, street-living youth might engage in fewer illegal activities given that they fear being apprehended by the police because of outstanding warrants or fear of being returned to the foster care system or to a parent's home. Alternatively, this finding might reflect a reporting bias, in which street-living youth underestimate (or shelter-residing youth overestimate) their illegal activities.

Homeless youth who live on the streets may be far more alienated from society than the shelterresiding youth. They may no longer consider their activity as falling outside social boundaries because they are alienated from the types of positive activity settings that might reinforce those boundaries. They consider their activities only in terms of personal survival and/or the needs of their immediate social group. Regardless of their self-reported recent illegal activities, the two groups did not differ in having ever been arrested, with two thirds of each sample reporting an arrest history.

\section{Limitations}

The current study is limited to a cross-sectional design and to a modified sample of convenience. A longitudinal design may be more appropriate for determining which shelter-residing youth are at risk for living on the streets, and if the difference between these youth is one of problem severity prior to homelessness or is better predicted by other factors.

The study used two modified convenience samples; however, the two samples may have differed on important characteristics that the present study could not measure. In addition, the street youth in this study accessed a drop-in center and were not completely disconnected from community services. Thus, both groups of youth accessed services and may share characteristics associated with openness to service utilization. However, the services provided by the shelter were institutionalized and stable while the services for the street-residing youth had fewer institutional-based links to the larger community.

Finally, all the youth in this sample also had substance use problems because of the inclusion criteria of the larger projects. However, several studies indicate that substance use among homeless youth is more common than uncommon and $69 \%$ to $71 \%$ of homeless youth (in other studies) report meeting the criteria for alcohol and/or illicit drug abuse disorders (Baer, Ginzler, \& Peterson, 2003; Kipke, Montgomery, Simon, \& Iverson, 1997). Substance use problems among adolescents are often associated with other related family, intrapersonal and interpersonal problems (Jessor \& Jessor, 1977), and might exacerbate problems associated with homelessness.

\section{Conclusions and Implications}

The youth in this study were sampled at one point in their homeless trajectory, and while a proportion of street-living youth reported a history of shelter involvement, few shelter youth (8\%) reported ever spending any nights on the streets. Overall, streetliving youth reported less lifetime system involvement than shelter-residing youth (only 34\% reporting having ever stayed overnight in a shelter). This means that specific intervention approaches for reintegrating runaway and homeless youth must go beyond that offered by the shelter system so that they deal with problematic behavior that are specific to life in fluid and disconnected activity settings such as the street. Interventions may need to be geared toward specific aspects of the activity setting such as family therapy for shelter involved youth whose parents are still involved in their lives and drop-in centers for street youth that include interventions tying youth back to larger social systems. When 
planning interventions for street youth, increasing system connections (relationships to social service providers) and barriers to such connections (trust and access) should be a primary focus, as this must occur prior to other more proximal intervention efforts (skills building and substance abuse treatment).

The present study has other important implications as well. Consistent with the findings from prior studies (Ensign \& Gittelsohn, 1998; Robertson \& Toro, 1999), the majority of street-living youth reported that they have never accessed services from shelters and have less overall system involvement, while most shelter-residing youth reported never sleeping on the streets. Since many street-living youth in this sample report never seeking shelter services, services directed towards reintegrating homeless youth must go beyond those offered by runaway shelters. The 1999 National Survey of Homeless Assistance Providers and Clients report that only 14 youth drop-in centers and 22 outreach programs exist in the U.S. that focus on serving homeless youth (Burt et al., 1999). Many cities do not have services, such as drop-in centers, available for homeless youth (Burt et al., 1999). The Good Samaritan Initiative (2003) that focuses on improving emergency shelters and permanent supportive housing for adults with a ten-year plan to end homelessness, neglect to address the service needs of street-living youth. Drop-in centers offer a bridge between homelessness and non-homelessness (Baron, 1999) and some research suggests that these programs can be a useful first step in the reintegration process (Slesnick et al., in press; Tsemberis et al., 2003).

This study shows that the two groups were similar in several respects that include the incidence of physical/sexual abuse and in the age when they first left home; however, street-living youth generally reported more severe problematic behavior and less system contact. The examination of the variables associated with and the role and impact of system involvement, as guided by ecological systems theory (Bronfenbrenner, 1979) may be of great utility to guide future research in understanding the development, maintenance and resolution of homelessness. Furthermore, the findings of the present study imply the necessity to increase the number of shelters and improve the quality of care systems at youth centers. In addition, it implies that the service programs for street-living youth should include HIV educational programs. It is important for street-residing youth to be recognized as having unique and varied needs so that more funding and strategic policy efforts can be directed towards reintegrating this underserved and underrepresented group.

\section{REFERENCES}

Baer, J. S., Ginzler, J. A., \& Peterson, P. L. (2003). DSMIV alcohol and substance abuse and dependence in homeless youth. Journal of Studies on Alcohol, 64, 514.

Baron (1999). Street youths and substance use: The role of background, street lifestyle, and economic factors. Youth \& Society, 31, 3-26.

Beck, A. T., Steer, R. A., \& Brown, G. K. (1996). BDI-II, Beck Depression Inventory: Manual (2 $\left.{ }^{\text {nd }} e d.\right)$. Boston, MA: Harcourt Brace.

Burt, M. R., Aron L. Y., Douglas T., Valente, J., Lee, E., \& Iwen, B. (1999). Homelessness: Programs and the People They Serve. Summary Report: Findings of the National Survey of Homeless Assistance Providers and Clients. Washington, DC: Urban Institute.

Chamberlain, C. \& MacKenzie, D. (2004). Youth Homelessness: Four Policy Proposals. Australian Housing and Urban Research Institute Final Report.

Clements, K., Gleghorn, A., Garcia, D., Katz, M., \& Marx, R. (1997). A Risk Profile of Street Youth in Northern California: Implications for Gender-Specific Human Immunodeficiency Virus Prevention. Journal of Adolescent Health, 20, 343-353.

Cooper, E. F. (2006). The Runaway and Homeless Youth Program: Administration, Funding, and Legislative Action. Congressional Research Service, Library of Congress. http://digital.library.unt.edu/govdocs/crs/ 
permalink/meta-crs-9962:1

De Rosa, C. J., Montgomery, S. B., Kipke, M. D., Iverson, E., Ma, J. L., \& Unger, J. B. (1999). Service utilization among homeless and runaway youth in Los Angeles, California: Rates and reasons. Journal of Adolescent Health, 24, 449-458.

Elliot, D. S., \& Huizinga, D. (1983). Social class and delinquent behavior in a national youth panel. Criminology: An Interdisciplinary Journal, 21, 149-177.

Ensign, J., \& Bell, M. (2004). Illness Experiences of Homeless Youth. Qualitative Health Research, 14, 1239-1254.

Ensign J., \& Gittelsohn, J. (1998). Health and access to care: Perspectives of homeless youth in Baltimore City, USA. Social Science and Medicine, 47, 2087-2099.

George, C. (2010. 5. 14). Number of young runaways found to be more than thought. Retrieved December 5, 2011 from http://www.chron.com/news/houston-texas/article/Number-of-young-runaways-foundto-be-more-than-1695129.php

Haber, M. G. \& Toro, P. A. (2004). Homelessness Among Families, Children, and Adolescents: An EcologicalDevelopmental Perspective. Clinical Child and Family Psychology Review, 7(3), 123-164.

Halcon, L. L., \& Lifson, A. R. (2004). Prevalence and predictors of sexual risks among homeless youth. Journal of Youth and Adolescence, 33, 71-80.

Jessor, R., \& Jessor, S. L. (1977). The social-psychological framework. In R. Jessor, \& S. L. Jessor. Problem behavior and psychosocial development: A longitudinal study of youth (pp. 17-42). Academic Press.

Johnson, T. P., Aschkenasy, J. R., Herbers, M. R., \& Gillenwater, S. A. (1996). Self-reported risk factors for AIDS among homeless youth. AIDS Education and Prevention, 8, 308-322.

Kann, L., Nelson, G. D., Jones, J. T., \& Kolbe, L. J. (1989). Establishing a system of complementary school-based surveys to annually assess HIV-related knowledge, beliefs, and behaviors among adolescents. Journal of School Health, 59, 55-58.

Kipke, M. D., Montgomery, S. B., Simon, T. R., \& Iverson, E. F. (1997). Substance abuse disorders among runaways and homeless youth. Substance Use and Misuse, 32, 969-986.

Kipke, M. D., O'Conner, S., Palmer, R. \& MacKenzie R. G. (1995). Street Youth in Los Angeles: Profile of a Group at High Risk for Human Immunodeficiency Virus Infection. Archives of Pediatric Adolescent Medicine, 149, 513-319.

Kurtz, P. D., Jarvis, S. V., \& Kurtz, G. L. (1991). Problems of homeless youths: Empirical findings and human services issues. Social Work, 36, 309-314.

Lee, Y., \& Choi, D. (2011. 2. 8). 6 out of 10 runaways are females. Retrieved December 5, 2011 from http:// www.seoul.co.kr/news/newsView.php?id=20110208 008016\# (Recited 2010 Korea National Police Agency data).

Lewit, E. M., \& Baker, L. S. (1996). Homeless families and children. The Future of Children, 6, 146-158.

McCarthy, B. \& Hagan, J. (1995). Getting into Street Crime: the structure and process of criminal embeddedness. Social Science Research, 21(1), 63-95.

McKinney, S. B. (1987). Stewart B. McKinney Homelessness Assistance Act. Pub. L.100-77, July 22, 1987, 101 Stat. 482, et seq.

Miller, W. R., \& DelBoca, F. K. (1994). Measurement of drinking behavior using the Form-90 family of instruments. Journal of Studies on Alcohol, Supplement No. 12, 112-118.

Molnar, B. E., Shade, S. B., Kral, A. H., Booth, R. E., \& Watters, J. K. (1998). Suicidal behavior and sexual/ physical abuse among street youth. Child Abuse $\mathcal{E}$ Neglect, 22, 213-222.

National Coalition for the Homeless (2000). Poverty versus pathology: What's "chronic" about homelessness. Retrieved August 27, 2007, from http://www. nationalhomeless.org/publications/chronic/full.html

National Coalition for the Homeless (1999). Illegal to be homeless: The criminalization of homelessness in the United States. Retrieved August 17, 2007, from http://www.nationalhomeless.org/publications/ crimreport/problem.html

National Youth Policy Institute (2009). Korean Survey on the Runaway of Youth and children in 2009.

Noh, H., Kim, H., \& Lee, J. (2005). A study on the 
psychological factors that influence suicidal thoughts and behaviors of runaway youths. Studies on Korean Youth, 16, 5-34.

Office of Technology Assessment (1991). Adolescent Health. Volume 2: Background and the Effectiveness of Selected Prevention and Treatment Services and Indexes to Volumes I, II, and III, Chapter 14 Homelessness: Prevention and Services. (pp. 663-692). Washington D.C. : Congress of the U.S.

Patel, D. R., \& Greydanus, D. E. (2002). Homeless adolescents in the United States. International Pediatrics, 17, 71-75.

Rhee, C., Noh, H., \& Lee, J. (2004). A comparative study of psychological characteristics of street youths and shelter youths: With a focus on victimization and related factors. The Korean Journal of Youth Counseling, 12, 83-95.

Robertson, M. J., \& Toro, P. A. (1999). Homeless youth: Research, intervention, and policy. In L. B. Fosburg, \& D. L. Dennis (Eds.), Practical Lessons: The 1998 National Symposium on Homelessness Research (pp. 3.1-3.32). Washington DC: U.S. Department of Housing and Urban Development and U.S. Department of Health and Human Services.

Rotheram-Borus, M. J., Koopman, C., Haignere, C., \& Davies, M. (1991). Reducing HIV sexual risk behaviors among runaway adolescents. Journal of the American Medical Association, 266, 1237-1241.

Rotheram-Borus, M. J., Song, J., Gwadz, M., Lee, M., Van Rossem, R. \& Koopman, C. (2003). Reductions in HIV Risk among runaway youth. Prevention Science, 4, 173-187.

Roy, E., Haley, N., Leclerc, P., Lemire, N., Boivin, J. F., Frappier, J. Y., \& Claessens, C. (2000). Prevalence of HIV infection and risk behaviours among Montreal street youth. International Journal of STD $\mathcal{E}$ AIDS, 11, 241-247.

Sameroff, A. J. (1983). Developmental systems: Contexts and evolution. In P.H. Mussen (Ed.), Handbook of child psychology: Vol I, History, Theory and Method. New York: Wiley.

Shaffer, D. (1992). The Diagnostic Interview Schedule for Children 2.3 Version. New York: Columbia University.

Slesnick, N., Kang, M., Bonomi, A., \& Prestopnik, J. (2008). Six and twelve month outcomes among homeless youth accessing therapy and case management through an urban drop-in center. Health Services Research. 43, 211-229.

Slesnick, N., Prestopnik, J. L. (2005). Ecologically based family therapy outcome with substance abusing runaway adolescents. Journal of Adolescence, 28, 277298.

Susser, E., Moore R., \& Link B. (1994). Risk factors for homelessness. Epidemiological Reviews, 15, 546-556.

Teare, J. F., Furst, D. W., Peterson, R. W., \& Authier, K. (1992) Family reunification following shelter placement: Child, family, and program correlates. American Journal of Orthopsychiatry, 62, 142-146.

Tonigan, J. S., Miller, W. R., \& Brown, J. M. (1997). The reliability of Form 90: An instrument for assessing alcohol treatment outcome. Journal of Studies on Alcohol, 58, 358-364.

Tsemberis, S. J., Moran. L., Shinn, M., Asmussen, S. M. \& Shern, D. L. (2003). Consumer preference programs for individuals who are homeless and have psychiatric disabilities: A drop-in center and a supported housing program. American Journal of Community Psychology, 32(3/4), 305-317.

U.S. Department of Health and Human Services. (1999). Runaway and Homeless Youth Program/Title 45, p. 300.

US House of Representatives, Education and Labor Committee (1992). Legislative history, juvenile justice and delinquency amendments. US Code of Law and Administrative News, House Report No. $102-756$.

Unger, J. B., Simon, T. R., Newman, T. L. Montgomery, S. B., Kipke, M. D., \& Albany, M. (1998). Early adolescent street youth: An overlooked population with unique problems and Service needs. Journal of Early Adolescence, 18, 325-348.

Van Leeuwen, J. M., Hopfer, C., Hooks, S., White, R., Petersen, J., \& Pirkopf, J. (2004). A snapshot of substance abuse among homeless and runaway youth 
in Denver, Colorado. Journal of Community Health, 29, 217-229.

Wagner, L. S., Carlin, L., Cauce, A. M., \& Tenner, A. (2001). A Snapshot of Homeless Youth in Seattle: Their Characteristics, Behaviors, and Beliefs about HIV Protective Strategies. Journal of Community Health, 26, 219-233.

Westerberg, V. S., Tonigan, J. S., \& Miller, W. R. (1998).

Reliability of the Form 90D: An instrument for quantifying drug use. Substance Abuse, 19, 179-189. Whitbeck, L. B. \& Hoyt, D. R. (1999). Nowhere to grow: Homeless and runaway adolescents and their families. Hawthorne, NY: Aldine de Gruyter.

Received September 30, 2011

Revised December 6, 2011

Accepted December 7,2011 